\title{
Effect of Adding Carbide Particles on The Mechanical Properties of Cast Aluminium 2024 Composites
}

\author{
Lamees faeq \\ lameessalam@yahoo.com \\ Iraq, Baghdad, University of technology
}

\begin{abstract}
The aluminium reinforced by particle composites has more attention due to its low cost with advantages such as good mechanical properties like wear resistance, hardness, and tensile strength. This research experimentally investigates Al 2024 matrix with boron carbides as reinforcement with different percentages $(1 \%, 2 \%$, and $3 \%)$ was produced by stir casting technique. This work investigates different properties such as mechanical behavior of boron carbides-reinforced aluminium matrix composites like tensile strength, wear, and hardness, and the effects of reinforcement fractions on these properties. The composite wear behavior is been investigated by dry sliding pined on disc machine with various parameters like distance, applied load, and weight percentage. All these properties like hardness and tensile strength have increased by increasing boron carbides contents. In wear, the weight loss has been obtained. The results show that the weight loss is increased by the increase in load and it decreases with the increase of boron carbide weight percentage. The optical microstructure revealed the homogeneous dispersion of boron carbide particles in the aluminium alloy.
\end{abstract}

Keywords: boron carbides, $\mathrm{Al} 2024$, wear, tensile strength, hardness.

\section{Introduction}

Reinforced aluminium composites emerge rapidly as materials engineering compared to ordinary alloys and metals. They are significantly acceptable due to higher wear strength, specific modulus, and specific strength compared with common unreinforced alloys [1]. Boron carbide has been considered to reinforce the particles. Aluminium alloy 2024 is having fatigue resistance, fine machining properties, and more strength than an alloy( 2017 and 2014). It highly utilized in airplane structures such as fuselage and wing structure. Furthermore, it is utilized in machines subjected to heat like automobile engines and different reciprocating and rotating parts like brake rotors, driveshafts, piston, and different structural parts requiring high strength materials and lightweight [2]. One of the main drawbacks of this material system is that they exhibit poor tribological properties. In material engineering, it is desired to produce a material having good tribological characteristics and higher wear resistance with the same weight to strength ratio which can lead to developing the material matrix composite $[3,4]$.

Ceramic particles like $\mathrm{Al} 2 \mathrm{O} 3$ and $\mathrm{SiC}$ are commonly utilized materials to reinforce alloy aluminium. (B4C) may replace $\mathrm{SiC}$ and $\mathrm{Al} 2 \mathrm{O} 3$ because of having higher hardness (only boron nitride and diamond have more hardness than it). "Boron carbide has attractive properties like low density $(2.52 \mathrm{~g} / \mathrm{cm} 3)$ and high strength, good wear strength, high hardness, and good chemical stability" [5]. "Composites are naturally or engineered take place materials made from two or more component materials with different chemical or physical characters that stay 
separate and distinct within the finishing structure". The form of materials consists of the matrix which is a continuous phase such as metals and polymers and the reinforcement which is discontinuous phase such as particulates, fibers, ceramics, and whiskers. On the other hand, the reinforcement withstands the percentage of the load while the matrix makes the load move by keeping them in touch [6]. The opportunities and challenges of aluminium matrix composite showed that it is noticeably better than $\mathrm{AL}$ alloy with no reinforcement [7]. The reinforcement phase addition highly enhances the characteristics of $\mathrm{Al}$ alloy. The concern in composites including low density is increasing (Seah et al., 2003, Sulaiman et al., 2008) Suggest Al-B4C composites applications such as hard disks substrate material, armor plates, and structural neutrons absorbent [8,9]. (Hapman et al., 1999, Blumenthal et al., 1994) [10, 11] (Lee et al., 2001) investigated the effect of reinforcement on the tensile strength of the Al-SiC and Al- B4C composites and noticed that $\mathrm{Al}-\mathrm{B} 4 \mathrm{C}$ strength is higher than the Al-SiC [12]. (1 Kundu et al., ) studied the hybrid metal matrix composites such as aluminium 6061 alloy composites reinforced with graphite, $\mathrm{SiC}$, and $\mathrm{A} 2 \mathrm{O} 3$ which are produced by stir casting technique. Dry Sliding Wear test was carried out for the materials and it has been noticed that it is considerably increased compared with Al6061 T6 alloy. Various parameters like sliding distance, sliding speed, and the load was considered which effects on wear rate [13]. (Rao and Das) investigated that the sliding distance influences on the wear behavior of $\mathrm{Al}-\mathrm{SiC}$ composite. It has been founded that wear rates increased by increasing the sliding speed and load. On the other hand, wear resistance enhanced by heat treatment [14]. (Sharma et al.) investigated the volume fraction influence of particles used as reinforcement with volume percentages of $1 \%-5 \%$ while wear tests were conducted with different sliding speeds and loads. It has been found from the results that the wear rates are decreased by an increase in the weight percentage of ceramics particles. Moreover, it is increased due to increasing the applied load and sliding speed [15]. (Lashgari et al.) investigates the influence of microstructure heat treating and tensile strength of Al-B4C composite They reported that mechanical properties are enhanced after heat treatment of the composites[16]. ( Sandeep Kumar Ravesh et.al.) carried out hardness and tensile tests at room temperature on MMC.

The study revealed that the MMCs hardness increased by an increase in the volume ratio of particles in the alloy matrix. The addition of ceramics 3particles can lead to enhance hardness due to the fact that the particles are having more hardness than Aluminium alloy that provides their hardness property to the matrix. It can be noticed from this investigation that tensile strength increases by an increase in the weight percentage of particles [17]. In this work boron carbide particles of different weight percentages $(1,2,3 \%)$ are reinforced in the Aluminium 2024 alloy matrix produced by stir casting technique. "Moreover, in this present work, the mechanical properties of stir cast Al-B4C composites like hardness, tensile strength, wear, and the microstructure was investigated".

\section{Experimental Part}

\subsection{Material used}

Aluminium2024 which contains copper and magnesium has been considered as matrix material while Boron- carbide has been considered as reinforcement material by using different weight percentages of it $(1 \%, 2 \%$, and $3 \%)$. Boron carbides were identified with X-ray diffract meter using (target: $\mathrm{Cu}$ ) radiation with scan step of 0.0500 degree and step time $0.6 \mathrm{sec}$. the 
image plate XRD system worked with (target: $\mathrm{Cu}$ ) radiation operating at $40.0 \mathrm{KV}$ and $30.0 \mathrm{~mA}$. The XRD pattern diffraction peaks have been compared with JCPDS with almost no defects respect to boron carbide pattern as shown in Fig.1

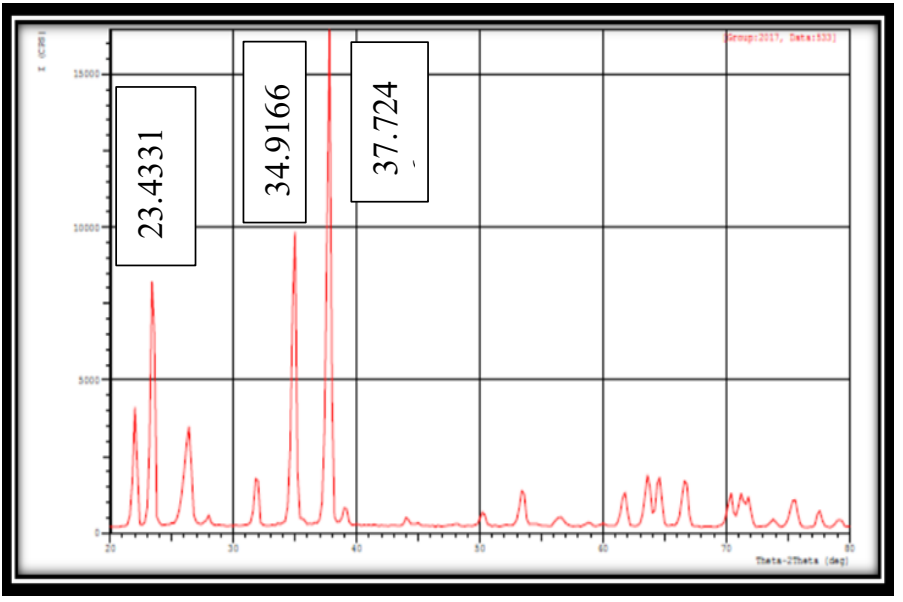

\subsection{Procedures}

Fig. 1. X-Ray diffraction (XRD) of boron carbide particle.

Stir casting method has been used to produce the metal matrix composites which is utilized in this research. The liquid matrix metal and the reinforcement sprinkled phase are been mixed by mechanical stirring then it is cast by a common cast method and produced by common metal shaping technology. The Aluminium boron carbide composite preparation is done depending on the mass percentage of $(1 \%, 2 \%$, and $3 \% \mathrm{a})$. The casted metal specimens are cleaned and melted to the temperature of $750 \mathrm{oC}$ in graphite crucibles. Fig.2 shows the set-up of the stir casting method. A furnace with a device to control temperature is utilized to melt the metal. The weight of the commercial (2024) aluminium is (100) gm and three different weights $(1,2$, and 3 ) $\%$ of (B4C) due to the weight percentages. The melted metal is degassed at (780o) C. B4C particles have been preheated to approximately $400 \mathrm{oC}$ to remove moisture then added to the melted metal and mixed constantly by a mechanical mixer at $720 \mathrm{oC}$. The mixing time is 10 minutes during stirring and $620 \mathrm{rpm}$ speed, The molten metal reinforced by boron carbide particulate is cast in a cylindrical mold. The casting temperature is $680 \mathrm{oC}$ then left to reach the solid-state in the molds. 


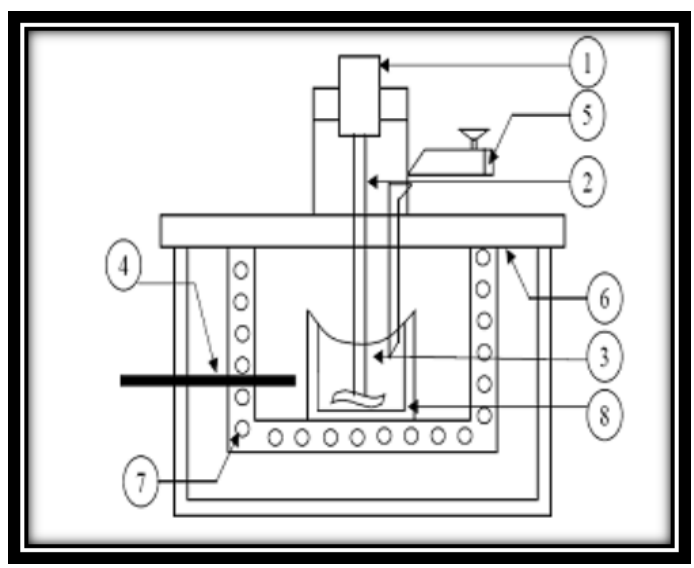

Fig. 2. Schematic set up for stir casting technique 1. Motor 2. Shaft 3.Molten aluminium 4.Thermocouple 5. Particle injection chamber 6. Insulation hardboard 7. Furnace 8. Graphite crucible.

\subsection{Characterization}

\subsubsection{Tensile Behavior}

The tensile test conducted based on (ASTM E8) at the temperature of the room by using the machine type WDW-200E with a strain rate of $(0.5 \mathrm{~mm} / \mathrm{min})$ and capacity $(20 \mathrm{KN})$ applied load. Standard specimens and the tensile behavior tests as shown in Fig.3.
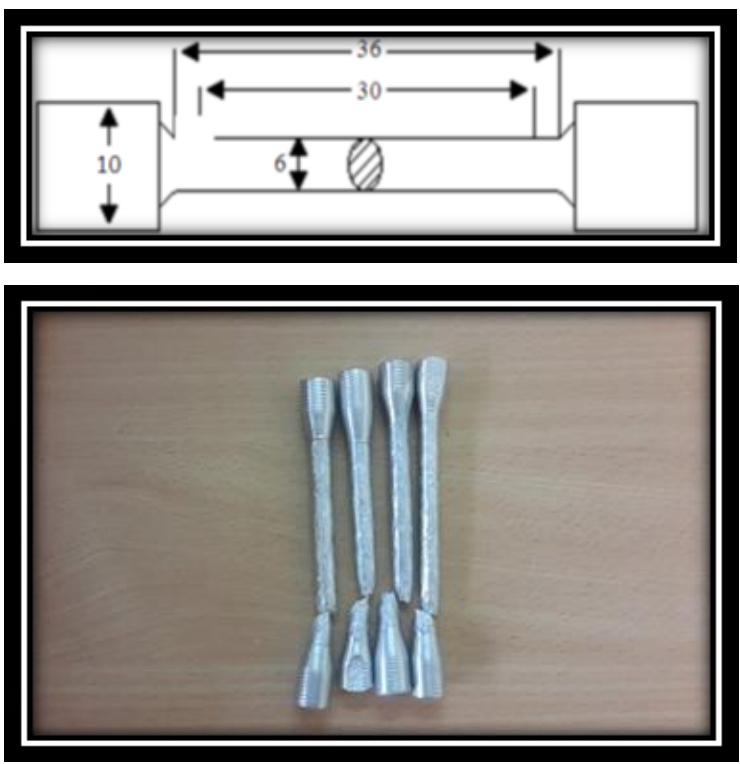

Fig. 3 Standard tensile specimen and tensile behavior tests. 


\subsubsection{Hardness}

Hardness tests were conducted on the unreinforced and composite specimens depending on the standard Vickers hardness test. The load applied was $30 \mathrm{~kg}$. Fig. 4 shows the hardness tests machine.

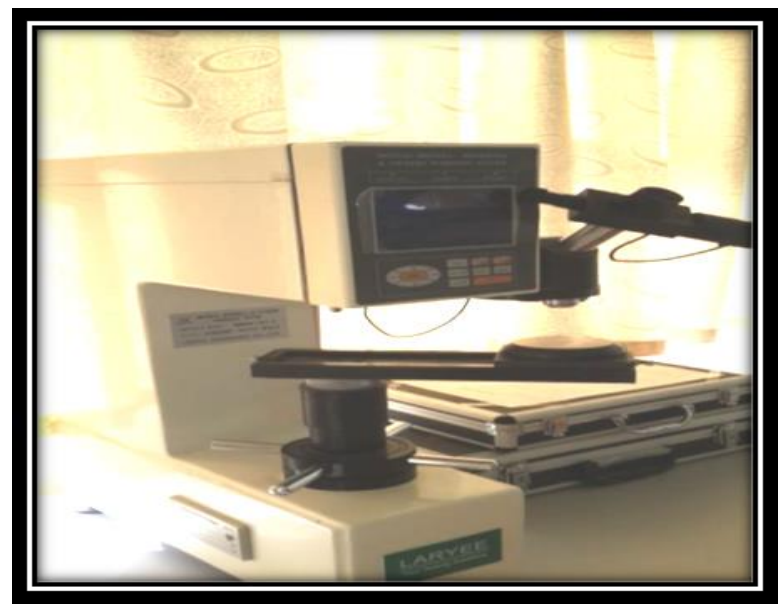

Fig. 4. Vickers hardness machine.

\subsubsection{Wear test}

Adhesion wear (Dry sliding wear) carried out at the temperature of the room depending on machine type (Pin on Disk) is used for measuring wear rate. Disk used is made from tool steel and has $385 \mathrm{HV}$. The specimen dimension of $6.5 \times 6.5 \times 30 \mathrm{~mm}^{3}$ was cut from the cast specimens. Figure 5 shows the wear machine. The wear tests have been carried out under different loads $5,10,15 \mathrm{~N}$, and the sliding speed of $950 \mathrm{rpm}$. Weight loss was measured at each loading conditions and different distance $(400,600) \mathrm{mm}$.

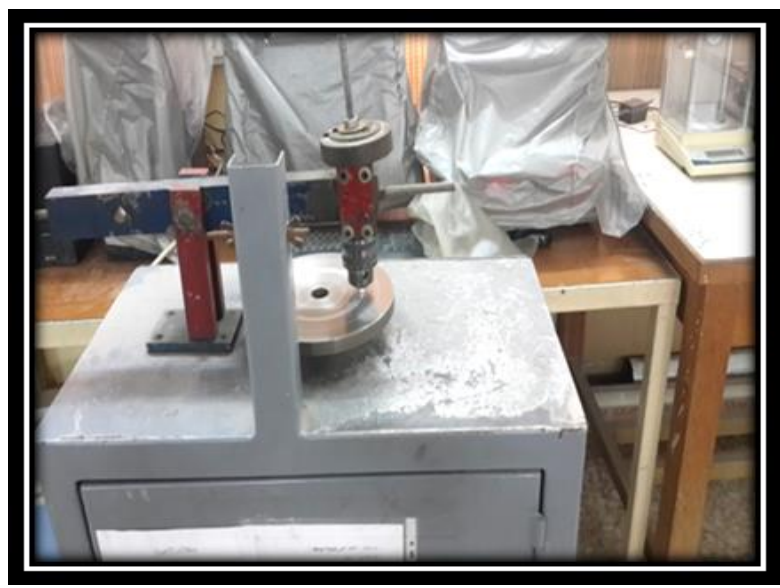

Fig. 5. The wear machine. 


\subsubsection{Microstructure test}

This test has been accomplished on specimens, grinding steps were performed with different papers ranging from 220 to 1200 grit. The polishing was carried out by polishing cloths using diamond paste. These samples were then cleaned with water and alcohol and dried, and the specimens were etched using $(\mathrm{HF}, \mathrm{H} 2 \mathrm{O})$ microstructure of specimens were observed with a magnification range of $20 \mathrm{X}$.

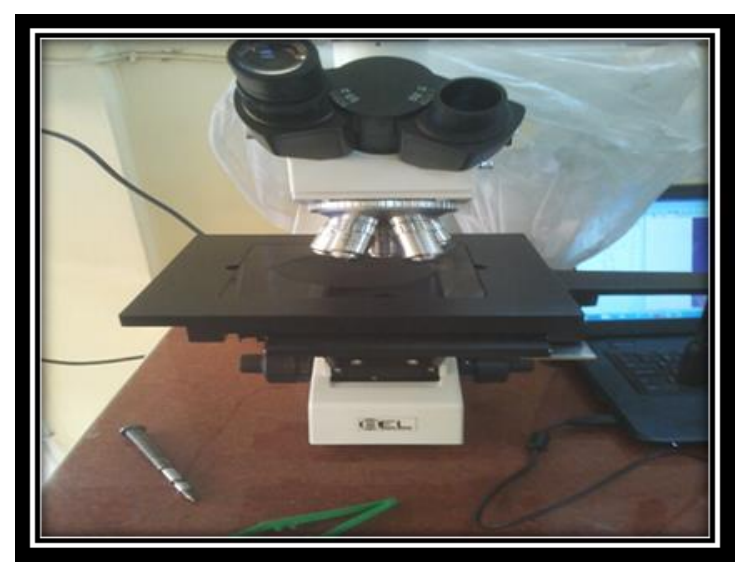

Fig. 6. Optical microscope.

\section{Results and Discussions}

\subsection{Tensile strength}

Fig. 7 observed that the tensile strength of the Al matrix composite material will increase compared with unreinforced Al. Young's modulus increased slightly with the boron carbide content Therefore the small size of boron carbide particles performed as barriers to the dislocations when withstanding the applied load. As the boron carbide particulate obstructs the front of advancing dislocation, thereby the matrix is strengthened, and Good bond of boron carbides particulate with the matrix, and the loads can be transferred to particle reinforcement through the interface is the cause of the behavior. In addition, mechanical stirring enhances the uniform distribution between boron carbide particles. The ultimate tensile strength has also enhanced with an increase in boron carbides weight percentage and compared to base metal it has increased by $3 \%$. 


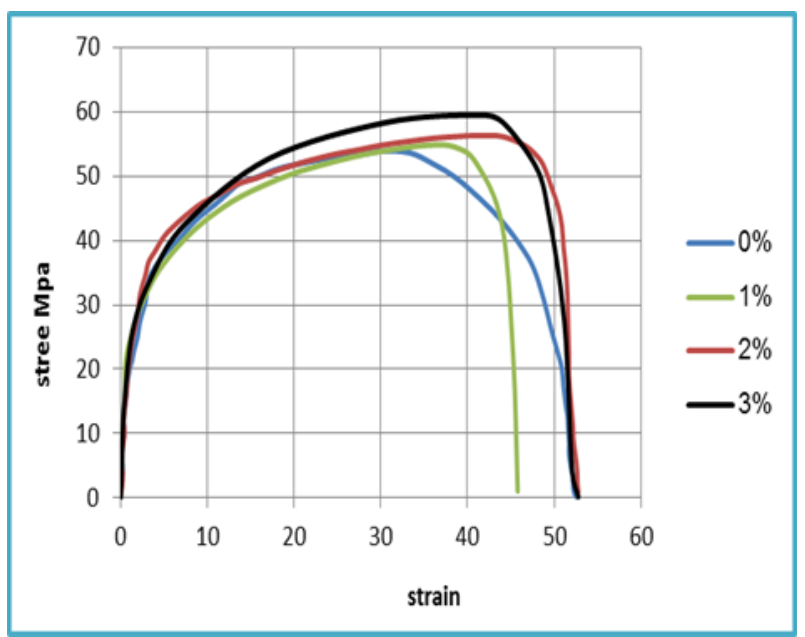

Fig. 7. Stress-strain curve for $\mathrm{Al}$ reinforced by boron carbide particles at different percentages and unreinforced $\mathrm{Al}$.

\subsection{Wear}

Fig. 7 observed weight loss as function as weight percentages of boron carbide particles and it is presented for $5 \mathrm{~N}, 10 \mathrm{~N}$, and $15 \mathrm{~N}$ at various distance traveled $40 \mathrm{~mm}$ and $60 \mathrm{~mm}$. From the graph below it is noticed that by increasing the load the weight loss also increases by the increase of the boron carbide content. Also, the weight loss of the composites and unreinforced $\mathrm{Al}$ has been increased by the increase in distance traveled. The sliding wear decreased considerably by adding the reinforcement material and the weight loss is decreased by adding boron carbide which is increased by comparing to unreinforced alloy. The aluminium reinforced by $3 \%$ boron carbide particles has less weight loss comparing to other weight percentages of boron carbide and unreinforced sample.

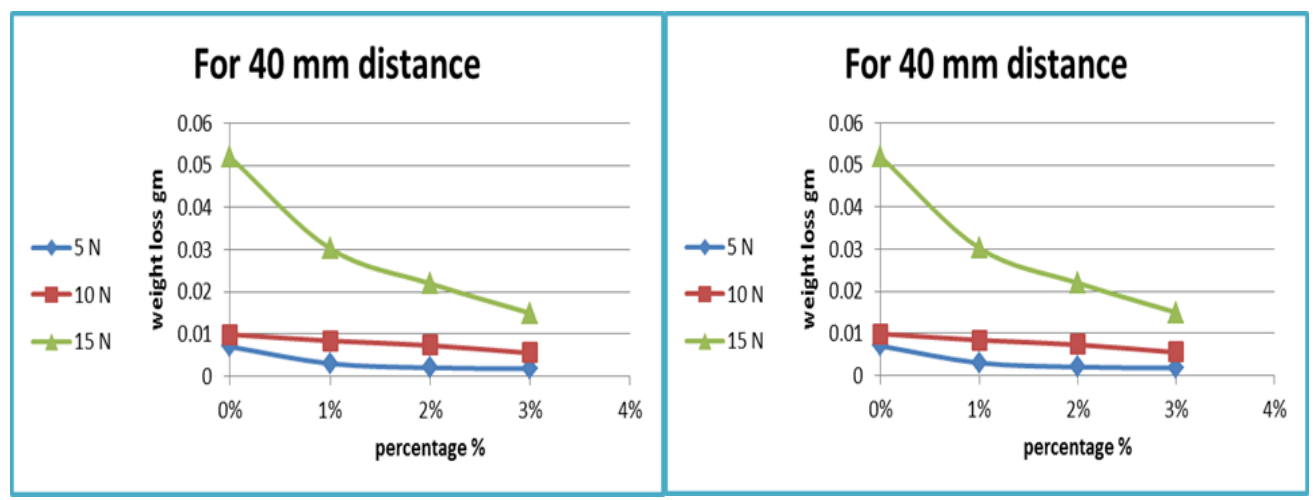

(a)

(b)

Fig. 8. Wear weight loss as function as percentages of boron carbide particles for different loads (5 N, 10 $\mathrm{N}$, and 15 . 


\subsection{Hardness}

The hardness value of the Aluminium 2024 alloy and Aluminium reinforced by boron carbides particles were evaluated depending on Vickers hardness testing with $30 \mathrm{~kg}$ load. An average of four readings was used for each value of hardness. The hardness value of $\mathrm{Al}$ 2024alloy and $\mathrm{Al}-\mathrm{B}_{4} \mathrm{C}$ composites are shown in fig. 8 . As the boron carbide content is increased, the composite hardness is increased. The average values of hardness, $0 \%, 1 \%, 2 \%$, and $3 \%$ specimens were measured to be 20,24.62,27.54, and $33 \mathrm{HV}$. The hardness improves due to the increase in the weight percentage of reinforced particles(B4C) which resulted from the very hard ceramics (B4C) particles in the aluminium alloy matrix, a higher constraint to the deformation of the localized matrix during indentation [18] and homogeneous distribution boron carbides particles.

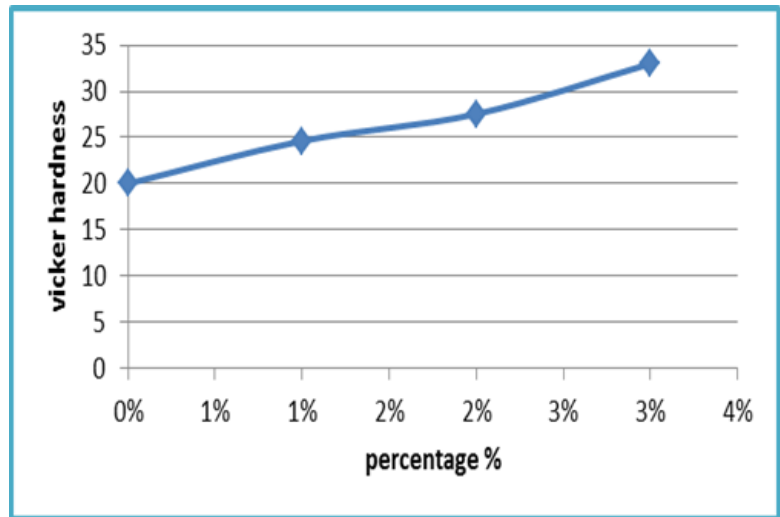

Fig. 9. Vickers hardness as function as percentages of boron carbide particles.

\subsection{Microstructure}

Boron carbide reinforced $\mathrm{Al}$ alloy composites with different weight percentages $(1 \%, 2 \%$, 3\%) are shown in Fig.10. It is observed that $\mathrm{B}_{4} \mathrm{C}$ particles are dispersed uniformly in the aluminium alloy for all weight percentages. This can be attributed to the effective stirring action and the use of appropriate process parameters.

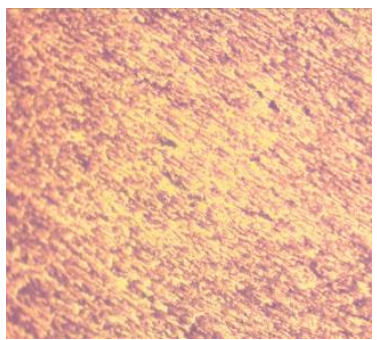

(a)

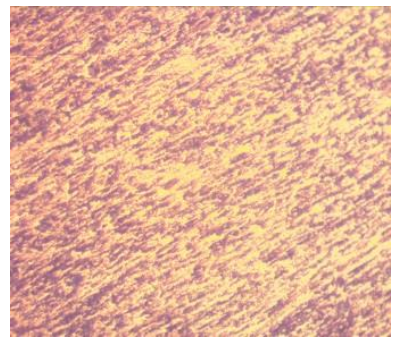

(b)

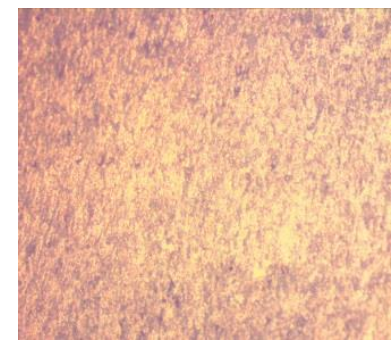

(c)

Fig. 10. Optical Microscope Image (20x) for the Specimen With (A) $1 \mathrm{Wt} \% \mathrm{~B}_{4} \mathrm{C}$;

(B) $2 \mathrm{Wt} \% \mathrm{~B} 4 \mathrm{C}$; and (C) $3 \mathrm{Wt} \% \mathrm{~B}_{4} \mathrm{C}$ 


\section{Conclusions}

1. The aluminium 2024 alloy composites consists of different percentages of boron carbide particles $(1 \%, 2 \%$, and $3 \%)$ were produced by stir casting method successfully.

2. Mechanical properties (tensile strength such as Young's modulus and ultimate tensile strength values and hardness) of $\mathrm{B} 4 \mathrm{C}$ reinforced $\mathrm{Al}$ alloy composites increased in comparison with unreinforced Aluminium alloy.

3. The commercial Aluminium wear resistance was significantly enhanced by adding Boron carbides particulate and the composite wear resistance was high compared to unreinforced aluminium over the entire load range tested $(5,10,15) \mathrm{N}$ under dry sliding conditions. This can be because of the favorable effect of the boron carbides particles. However, the addition of $3 \mathrm{wt} \%$ boron carbides particles to the $\mathrm{Al}$ was highly effective to decrease its wear loss.

\section{References}

[1] Sarkar, S. and Singh A.: Studies on aluminium-iron ore in-situ particulate composite. Open J. Comp.Mater., 2: 22-30. DOI: 10.4236/ojcm.2012.21004 (2012).

[2] Ibrahim, I.A., F.A. Mohamed, E.J. Lavernia: Metal matrix composites-a review. J. Mater. Sci., 26: 1137-1157. DOI: 10.1007/BF00544448 (1991).

[3] Buraimoh, A.A., Ojo S.A., Hambolu J.O. and Adebisi S.S.: Aluminium chloride exposure had no effects on the epididymis of wistar rats. Am. Med. J., 3: 210-219. DOI: 10.3844/amjsp.2012.210.219, (2012).

[4] Sinclair, I. and Gregson P.J.: Structural performance of discontinuous metal matrix composites. Mater. Sci. Technol., 3: 709-726. DOI: 10.1179/026708397790290254(1997).

[5] Sannino, A.P. and Rack H.J.: Dry sliding wear of discontinuously reinforced aluminium composites: Review and discussion. Wear, 189: 1-19. DOI: 10.1016/0043-1648(95)06657-8(1995).

[6] Mohanty M. , Balasubramanian K, Seshadri S.K.: Boron carbide-reinforced aluminium 1100 matrix composites: fabrication and properties. Materials science and engineering, 498, p 42-52Pai, B.C., T.P.D. S(2008).

[7] Surappa M.K: Aluminium matrix composites: Challenges and opportunities. Sadhana, 28: 319-334. DOI: 10.1007/BF02717141,( 2003).

[8] Seah H.W., Hemanth J., Sharma S.C.:Mechanical properties of aluminium/quartz particulate composites cast using metallic and non metallic chills. Materials and design, 24, p 87-93(2003).

[9] Sulaiman S., Sayuti M., Samin R:Mechanical properties of the as cast quartz particulate reinforced LM6 alloy matrix composites. Journal of materials processing technology, 201, p 731-735(2008).

[10] Chapman T.R., Niesz D.E., Fox R.T., Fawcett T.:Wear-resistant aluminium-boron-carbide cermets for automotivebrake applications',Wear,236,p81-87(1999).

[11] Blumenthal W.R., Gray G.T., Claytor T.N: Response of aluminium-infiltrated boron carbide cermets to shock wave loading. Journal of material science, 29/17, p 4567-4576(1994).

[12] Lee B., Sim H.S., Cho S.Y,. Kwon H: Tensile properties of $5052 \mathrm{Al}$ matrix composites reinforced with B4C", Metallurgy and materials transactions-A 32, p 2142-2147(2001).

[13] Satpal Kundu, Ro. B.K., Ashok Kr Mishra: Study of Dry Sliding Wear Behavior of Aluminium/Sic/A12O3/Graphite Hybrid Metal Matrix Composite Using Taguchi Technique. International Journal of Scientific and Research Publications, 3 (2), 1-8(2011).

[14] Rao R. N. and Das S.: Effect of Sliding Distance on the Wear and Friction Behavior of as Cast and Heat-Treated Al-SiCp Composites. Materials and Design, 32 (5), 3051-3058(2011).

[15] Sharma S. C., Girish B. M., Kamath R. and Satish B. M.: Effect of Sic Particle Reinforcement on the Unlubri- cated Sliding Wear Behavior of ZA-27 Alloy Composites.Wear, 213(1-2), 33-40(1997). 
[16] Lashgari H.R, Zangeneh Sh., Shahmir H., Saghafi M., Emamy M.: Heat treatment effect on the microstructure, tensile properties and dry sliding wear behavior of A356-10\% B4C cast composites. Materials Design 31, p 4414-4422(2010).

[17] Sandeep Kumar Ravesh, Garg T. K.: Prepration \& Analysis For Some Mechanical Property Of Aluminium Based Metal Matrix Composite Reinforced With Sic \& Fly Ash. IJERA, vol.2, issue6, pp.727-731(2012)

[18] Lu L., Lim C.Y.H., Yeong W.M.: Effect of reinforcement on strength of Mg9\% Al composite. Composites structure, 66, p 41-45, (2004). 